one outcome of the litigation which lies ahead may be a decision that companies which dominate a market must show greater restraint than their rivals.

The case against IBM's traditional practice of lumping together its charges for hardware and software is at once more complicated and more likely to emerge as the kind of issue on which the courts may decide that IBM should be broken up. To begin with, it seems to be agreed that this procedure has helped to fix the rental charges of IBM computers well above those which would derive from the bare cost of the machinery, particularly because of the thrifty rule by means of which IBM has been writing off the initial cost of its hardware in four years. To begin with, this comparatively high costing procedure has angered customers wishing to provide their own software for rented IBM equipment. More recently, especially since IBM and other manufacturers have becn required to offer the rental and outright sale as free alternatives, this pricing policy has provided room in the market for the computer rental companies such as Data Processing to buy IBM equipment and rent it out at 10 per cent below IBM prices.

IBM announced in mid-December that it had embarked on a study of pricing policy and that it was hoping to devise a new scale of charges by July this year. The need to charge separately for hardware and software seems to have been acknowledged, though the corporation has given no hint of how this may be done. What the leasing companies would no doubt like to see is an arrangement by means of which IBM would be compelled to provide second and third users of hired IBM equipment with the kind of systems analysis which it provides for its own customers and which it is said now to deny to those who rent used equipment from the leasing companies. Other would-be entrants to the computer industry would also wish to see a situation in which they can compote with IBM on software without having to provide customers with computers as well.

Unfortunately for the Department of Justice, it is by no means obvious how this kind of separation between hardware and software is to be brought about. IBM is not the only computer manufacturer which considers software to be inseparable from marketing. It is also possible that if a separation could be achieved, it would be even easier for successful companies to establish a monopoly position than in the supply of hardware, if only because of the disproportionate advantages of having accumulated a large library of programs.

In these circumstances, the litigation ahead can hardly be swift. It is also plain that IBM will do its best to be a moving target. The most serious portent may simply be that the months ahead promise to be a worrying time for the large corporations based on electronics-it seems to be widely understood that the unpublished report of the task force which has been studying the telecommunications satellites is anxious to clip the wings of AT \& T still further.

\title{
AWARDS
}

\section{National Medal of Science}

ThE National Medal of Science was presented last week to twelve more American scientists, bringing the total number of awards since the medal was first struck in 1962 to 51 . The 1968 winners were drawn from most of the major disciplines in engineering and science-five biological scientists, two engineers, a mathematician and four physical scientists.

Dr Detlev W. Bronk, the retiring president of the Rockefeller University and hitherto a powerful voice on Washington's science councils, received the medal for his studies of the human nervous system. Dr B. Frederick Skinner of Harvard University, the experimental psychologist of Skinner Box fame, who is at present on sabbatical leave at the University of Cambridge, was cited for his experimental analysis of animal learning, conditioning and behaviour. Dr Jay L. Lush of Iowa State University was citcd for his animal breeding work. Dr H. Albert Barker of the University of California, well known to biochemists for his work on fatty metabolism and vitamin $B_{12}$, received the medal for his studies on the impact of chemistry on biology. Bernard B. Brodie, head of the National Institutes of Health chemical pharmacology laboratory, was one of two government scientists in the list. The other was Dr Herbert Friedman of the US Naval Research Laboratory, a founding father of X-ray astronomy, who as early as 1948 was using V2 rockets to make X-ray observations of the Sun and to map
X-ray emission throughout a sunspot cycle. Dr Lars Onsager of Yale University now has the medal to add to the 1968 Nobel Prize for chemistry, and Eugene P. W: gner of Princeton, the atomic physicist who argues that biological systems represent more than the sum of their parts, received the medal for his work on the atomic nucleus. Dr Paul D. Bartlett, the organic chemist from Harvard University, had the distinction of having both his research and his work as a brilliant teacher recognized in the citation, which reads: "for advancing our understanding of mechanisms by which chemical reactions take place, and for success in training young teachers and researchers".

The two engineers who received the medal were Dr John P. Eckert of the Sperry Rand Corporationthe only industrial scientist in the list-for his work on improving digital computers, and Dr Nathan $M$. Newmark of the University of Illinois. Newmark has developed widely used methods for analysing structural components under various loading conditions.

Dr Jerry Neyman of the University of California at Berkeley was cited for his work on modern mathematical statistics, but he is more widely known for criticisms of the Vietnam War which led the Office of Naval Research to query his position before it rencwed a research contract. All ended happily when the Pentagon stepped in, and now by all accounts the issue is closed and the contract renewed. 